\title{
OS PRINCÍPIOS ELEITORAIS E OS DIREITOS FUNDAMENTAIS
}

\author{
ELECTORAL PRINCIPLES AND FUNDAMENTAL RIGHTS
}

\author{
Ana Beatriz Jorge de Carvalho Maia ${ }^{1}$
}

\begin{abstract}
Resumo: O presente trabalho tem como objetivo analisar os princípios do direito eleitoral, tanto os constitucionais quando os da propaganda, e sua relação com o exercício dos direitos fundamentais. A metodologia utilizada foi a pesquisa documental, bibliográfica e empírica, utilizando-se de material já publicado. Quantos aos procedimentos, foi utilizado o método qualitativo na análise e o dedutivo na aplicação aos casos práticos. Em um primeiro momento se fez necessário tecer comentários acerca da normatividade dos princípios, com o estudo da divisão das normas em regras e princípios, conforme ensina Dworkin. Em seguida foi abordado em linhas gerais os aspectos dos direitos fundamentais e esclarecer qual a sua relação com os princípios. Como tópico principal foi discorrido acerca dos princípios constitucionais eleitorais sob a ótica da dinâmica dialética citada. No mais, foi discorrido sobre o conceito e os princípios da propaganda eleitoral e seus reflexos direto no exercício da cidadania, da representatividade e o do Estado Democrático de Direito por meio da influência ao voto e sobre a tutela empregada na propaganda eleitoral. Os principais resultados encontrados apontam para o entendimento de que o voto é um direito constitucional protegido pelos princípios eleitorais, não podendo sofrer influências danosas que possam prejudicar a liberdade de expressão do cidadão, por meio de propaganda enganosa ou fake news, pois se trata de um direito absoluto, não admitindo-se o eleitor seja induzido a erro.
\end{abstract}

Palavras-chaves: Direito Eleitoral; Princípios; Direitos Fundamentais; Propaganda; Influência.

\begin{abstract}
This work aims to analyze the principles of electoral law, both constitutional and propaganda, and their relationship with the exercise of fundamental rights. The methodology used was documentary, bibliographical and empirical, using material already published. As for the procedures, the qualitative method was used in the analysis and the deductive method in the application to practical cases. At first, it was necessary to comment on the normativity of principles, with the study of the division of norms into rules and principles, as taught by Dworkin. Then, the aspects of fundamental rights were discussed in general terms and their relationship with the principles was clarified. As a main topic, it was discussed about the electoral constitutional principles from the perspective of the dialectical dynamics. Furthermore, it was discussed the concept and principles of electoral advertising and its direct reflections on the exercise of citizenship, representation, and the Democratic Rule of Law through the influence of voting, and also discussed about the tutelage employed in electoral advertising. The main results found point to the understanding that voting is a constitutional right protected by electoral principles and cannot suffer harmful influences that may harm the freedom of expression of the citizen, through misleading advertising or fake news, as this is an absolute right and the voter cannot be misled.
\end{abstract}

Keywords: Electoral Law; Principles; Fundamental Rights; Advertising; Influence.

\section{Introdução}

No corpo da Constituição estão implícitos, em seus textos, diversos dispositivos atinentes aos princípios e aos direitos fundamentais. Não há dúvidas quanto à influência destes no demais ramos do Direito, tendo em vista que a dignidade da pessoa humana diz respeito a maior aspiração da sua vida. Isso porque a Constituição da República Portuguesa possui supremacia,

\footnotetext{
${ }^{1}$ Mestranda em Ciências Jurídicas, Universidade Autónoma de Lisboa (UAL), e-mail: anabeatriz@tjma.jus.br
} 
de modo que os princípios constitucionais ganham cada vez mais força na aplicação do Direito, não se restringindo ao aspecto axiológico, mas atuando como norma a ser cumprida.

Com efeito, as regras e os princípios oriundos do Direito Eleitoral possuem caráter cogente, especialmente quanto normatizam as relações entre os particulares e os órgãos, agentes públicos e entidades, fornecendo uma estrutura apta ao pleno exercício das atividades políticas que possuem como objetivo, em tese, o interesse público. Tal propósito possui fundamento no regime democrático e na operacionalização do Estado Democrático de Direito.

Todavia, não há de se falar em democracia sem se falar em voto, uma vez que este é o instrumento hábil do cidadão na escolha de seus representantes e possui importância até mesmo nas decisões que exigem participação direta, como é o caso de referendos e plebiscitos. Neste ponto, é importante salientar que os princípios do Direito Eleitoral não se limitam aos constitucionais e aos processuais, há também aqueles que atuam na disciplina da campanha política, em especial a propaganda eleitoral. Uma vez que é por meio da propaganda eleitoral que os candidatos a representantes políticos implantam as suas mensagens na mente dos eleitores, na qualidade de receptadores.

Se um lado temos o direito fundamental à liberdade de expressão, de outro temos os princípios da legalidade, do poder de polícia ex officio e outros que são princípios eleitorais que regem a propaganda e que possuem como fim a limitação do exercício do direito à propaganda, haja vista não se tratar de um direito absoluto.

Em face do exposto, este trabalho tem como finalidade a demonstração da interligação entre princípios eleitorais e os direitos fundamentais, de modo a esclarecer que os princípios não são meros axiomas, possuindo caráter de norma, razão pela qual possuem tanta força na regulamentação da propaganda eleitoral que é o principal meio de captação de votos.

No que cerne à metodologia empregada, o presente estudo utilizou-se da pesquisa documental, bibliográfica e empírica. Em especial, a pesquisa bibliográfica que foi a principal fonte, tendo em vista que se trata de tema amplamente discutido por grandes doutrinadores. No mais, salienta-se que foi utilizado o método qualitativo na análise e o método dedutivo na aplicação aos casos práticos.

\section{Desenvolvimento}

\subsection{Considerações acerca da normatividade dos princípios}

A norma jurídica é o gênero, que se subdivide em duas espécies: princípios e regras. Segundo Aragão (2005), com fundamento nos estudos de Dworkin, a teoria de Alexy 
denominada de normativa-material assegura que toda norma é composta por regras ou princípios, de modo que a diferença consiste apenas no campo qualitativo, baseada na forma de resolução de conflito.

Isso porque, princípios são considerados mandados de otimização, passível de cumprimento em maior ou menor grau, a partir da ponderação entre a perspectiva jurídica e a condição real de subsunção do fato à norma. Nesse sentido, Alexy afirma que "o princípio é norma ordenadora de que algo se realize na maior medida possível, dentro das possibilidades jurídicas e reais existentes" (CUNHA JÚNIOR 2012, p. 155).

Àvila (2014) definiu princípios como "normas que estabelecem fundamentos para que determinado mandamento seja encontrado, enquanto, para ele as regram determinar a própria decisão".

Segundo Dworkin (2013) a diferença entre regras e princípios dentro do campo da norma está descrita em dois modelos. O primeiro modelo e o das regras, o qual recebeu a denominação de aplicabilidade de tipo tudo-ou-nada. Isso porque, há hierarquia entre as regras, de modo que a aplicação de uma afasta a outro, não havendo validade concomitante.

Assim, colaciona-se o trecho de Dworkim (2013 p. 43):

Nesse sentido, uma regra jurídica pode ser mais importante do que outra porque desempenha um papel maior ou mais importante na regulação do comportamento. Mas não podemos dizer que a regra é mais importante que outra enquanto parte do mesmo sistema de regras, de tal modo que se duas regras estão em conflito, uma suplanta a outro em virtude de sua maior importância.

O segundo modelo, de acordo com o jurista, está no plano dos pesos, inexistindo nas regras, se aplicando exclusivamente aos princípios. Isso porque, os conceitos e as noções axiológicas se tornam mais agudas, diante dos chamados casos difíceis, composto pelo conflito entre princípios.

No momento em dois ou mais princípios se colidem, prepondera o que, mediante as vicissitudes do caso concreto, tenha prioridade. Todavia, a preponderância de um princípio em um determinado embate, não importa na ineficácia ou inferioridade do princípio oposto. Desse modo, infere-se que o conflito de regras é solucionado a luz do plano da validade. Por outro lado, a antinomia principiológica é resolvida na dimensão de peso.

\subsection{Considerações acerca do direito fundamental}

Segundo Mazzuoli (2018, p. 31), tais direitos são expressões inerentes ao resguardo interno dos direitos dos indivíduos, ligadas aos mandamentos constitucionais de proteção, de 
modo que já estão devidamente positivadas nas constituições contemporâneas. Conforme prelecionar o citado autor "são direitos garantidos e limitados no tempo e no espaço, objetivamente vigentes numa ordem jurídica concreta".

Caso não haja previsão acerca dos direitos fundamentais do documento constitucional, há a perda da própria função social da constituição. Nesse sentido, assevera o famigerado Art. 16 da Declaração dos Direitos do Homem e do Cidadão 1789: "A sociedade em que não esteja assegurada a garantia dos direitos nem estabelecida a separação dos poderes não tem Constituição".

Segundo Novais (2018), a concepção dos direitos fundamentais como peça chave do Estado de Direito possui raiz no aspecto indisponível dos direitos fundamentais pelos órgãos e poderes públicos. Haja vista que o poder político é vinculado à observância dos citados direitos, mesmo que o representante político tenha o seu poder legitimado pelo voto de maneira democrática, ainda assim, não poderia violar garantias fundamentais do povo. Para melhor elucidação convém colacionar o seguinte trecho de Novais (2018, p. 25):

Essa ideia de indisponibilidade de um domínio furtado à decisão democrática - que no fundo é o coração do constitucionalismo e, por isso, a concepção dos direitos como trunfos não é mais que uma decorrência lógica da existência de uma constituição em sentido formal -, encontra o seu fundamento material no reconhecimento a cada titular de direitos fundamentais de uma dignidade como pessoa. É, em uma última análise com base e por causa da dignidade da pessoa humana que se reivindica a delimitação de uma esfera de autonomia e de liberdade individuais de que o Poder não pode dispor livremente e que está juridicamente obrigar a respeitar, a proteger e a promover.

Portanto, resta inconteste que os direitos fundamentais constituem um parâmetro axiológico-moral com poder coercitivo, de modo que são indisponíveis, não competindo as autoridades estatais decidirem quais serão positivados na Constituição ou quais serão garantidos e realizados. Caracteriza-se, então, a inalienabilidade do contrato social pactuado entre o Estado e o seu povo.

\subsection{Relação entre princípios e direitos fundamentais}

É tênue a linha entre os princípios e os direitos fundamentais, isto porque a base axiológica dos direitos fundamentais é o princípio da dignidade humana, que se desdobra em diversas vertentes. Em outras palavras, os princípios podem ser entendidos como razões para as regras.

Vale frisar a importância do princípio da dignidade da pessoa humana na raiz do entendimento em torno da natureza e dos objetivos dos direitos fundamentais no Estado 
Democrático de Direito. Segundo Novais (2018) os direitos fundamentais estão presentes em todas as Constituições, todavia, em uma sociedade estruturada politicada e alicerçada nos valores da dignidade da pessoa humana os direitos fundamentais representam, na qualidade de norma jurídica de força constitucional, elemento essencial a garantia da liberdade, igualdade, autonomia e bem-estar dos cidadãos.

Sob uma ótica distinta, Alexy orienta que as normas intituladas de direitos fundamentais devem ser interpretadas como princípios, de modo a possibilitar que haja diversos resultados de sopesamento em caso de conflito, tendo em vista que não há hierarquia entre direitos fundamentais. Em que pese a abstração da valoração das normas, a depender do caso concreto, é válido destacar que os interpretadores da constituição não possuem poderes plenos, uma vez que o sistema híbrido de que soma regras e princípios é justamente para proteger a eficácia da Constituição (ARAGÃO, 2005, n. p.).

Dito isto, Ávila (2014, p. 64) explica que "os princípios não determinam absolutamente a decisão, mas somente contêm fundamentos, os quais devem ser conjugados com outros fundamentos provenientes de outros princípios". Ainda sob a ótica do mesmo jurista, enfatizase a extrema importância dos princípios na Constituição, pela grande extensão que possuem junto aos direitos fundamentais individuais, como por exemplo direito à liberdade e a igualdade, bem como nos interesses coletivos. Nestes casos, os princípios são garantidores dos direitos fundamentais.

Outro aspecto relevante é a tarefa dos princípios na delimitação do próprio teor normativo dos direitos fundamentais. Uma vez que ao delimitar o conteúdo dos referidos direitos há uma orientação para que seja conferido maior peso à autonomia do titular do direito. Por conseguinte, a dignidade da pessoa humana se apresenta, segundo Novais (2018, p. 33), como "fundamento da diferenciação das possibilidades de cedência posterior dos direitos fundamentais e, por último, está essencialmente na base dos critérios de filtragem das razões admissíveis para a sua eventual limitação".

No que cerne ao direito eleitoral, objeto do presente estudo, os princípios são extremamente importantes, pois segundo Canotilho (2003, p. 412) é possível verificar “princípios definidores da forma de Estado, dos princípios definidores da estrutura do Estado, dos princípios estruturantes do regime político e dos princípios caracterizadores da forma de governo e da organização política em geral". Estes possuem relações muito próximas com determinados direitos fundamentais, mas tal interligação vai ser melhor elucidada no tópico a seguir. 
2.4 Princípios constitucionais do Direito Eleitoral e suas relações com o Direito Fundamental

Embora o direito eleitoral seja um ramo autônomo do Direito, possui intensa ligação com o direito constitucional, não podendo ser desvencilhado do mesmo. A função precípua a ser realizada pelo Direito Eleitoral é de regulamentação por meio de um processo ordenado das disciplinas que envolvem o processo eleitoral e transferir não só os direitos, como também os deveres do povo na constituição do governo, de acordo com a forma de governo adotada.

Nas palavras de Pimentel (2019), o direito processual eleitoral possui autonomia em relação aos seus princípios por meio da especialidade desse campo do direito. Conforme lições de Ferreira (2003) os princípios se dividem em dois grupos: princípios informativos e os princípios gerais do processo.

\subsubsection{Princípio democrático}

De acordo com Canotilho (2003), se trata de um princípio político constitucional estruturante que o materializa juridicamente como um Estado Democrático de Direito.

A Constituição portuguesa atribui valor ao princípio democrático em se Artigo $2^{\circ}$ :

A República Portuguesa é um Estado de direito democrático, baseado na soberania popular, no pluralismo de expressão e organização política democráticas, no respeito e na garantia de efectivação dos direitos e liberdades fundamentais e na separação e interdependência de poderes, visando a realização da democracia económica, social e cultural e o aprofundamento da democracia participativa.

Tal princípio reproduz as vertentes da teoria democrática representativa, os quais sejam a separação de poderes, o pluripartidarismo, eleições e representatividade por órgãos. Outro fato relevante é que o princípio democrático se revela como o instrumento capaz de possibilitar aos cidadãos a participação nos processos de decisão, o exercício crítico perante a divergência de convicções, por meio do ordenamento de processos.

Nesse sentido, dispõe Canotilho (2003. p. 415-146):

Com a consagração de uma inequívoca dimensão representativa do princípio democrático, a Constituição teve em conta não só a mudança estrutural desta dimensão nos modernos Estados, mas também a necessidade de dar eficiência, selectividade e racionalidade ao princípio democrático (orientação de 'output').

Não há dúvidas de que o citado princípio é uma das bases constitutivas do Estado de Direito. Entretanto, para a execução do princípio democrático exsurge os direitos fundamentais que se caracterizam como elemento primordial, atuando no plano axiológico do mesmo. Para 
melhor elucidação, especifica-se que uma vez que o princípio democrático garante a todos os cidadãos elegíveis o direito de partição política ativa, tem-se o reflexo direto do direito fundamental da igualdade e da participação política, conforme Art. $48^{\circ}$ da Constituição Portuguesa.

Quanto à participação livre assente esta é assegurada pelo princípio em estudo, sendo uma forma de garantia do direito de associação, de liberdade de expressão e de formação de partido político. Ademais, está ligado intrinsicamente ao processo de abertura político para a criação de direitos sociais, económicos e culturais, nos termos do Art. $2^{\circ}$, os direitos fundamentais se caracterizam como elemento primordial para a execução do próprio princípio democrático.

Realce-se esta dinâmica dialética entre os direitos fundamentais e o princípio democrático. Ao pressupor a participação igual dos cidadãos, o princípio democrático entrelaça-se com os direitos subjetivos de participação e associação, que se tornam, assim, fundamentos funcionais da democracia. Por sua vez, os direitos fundamentais, como direitos subjetivos de liberdade, criam um espaço pessoal contra o exercício de poder antidemocrático, e como direitos legitimadores de um domínio democrático asseguram o exercício da democracia mediante a exigência de garantias de organização e de processos com transparência democrática (princípio maioritário, publicidade crítica, direito eleitoral).

Por fim, na qualidade de direitos subjetivos a prestações sociais, económicas e culturais, os direitos fundamentais constituem dimensões impositivas para o preenchimento intrínseco, através do legislador democrático, dessas garantias. Foi esta compreensão que inspirou logo o Art. 2. ${ }^{\circ}$ da CRP (Constituição da República Portuguesa de 1976) ao referir-se a Estado democrático baseado na soberania popular e na garantia dos direitos fundamentais.

\subsubsection{Estado Democrático de Direito}

Ainda que se tenha conhecimento de que a conceituação clássica de Estado já está superada por parte da doutrina, para este trabalho, entender-se-ão por elementos do Estado o tradicional tripé: povo, território e estado soberano. Em outras palavras: Estado é uma associação de pessoas que vivem em certo território sob o comando de uma autoridade.

A previsão legal do princípio supracitado encontra-se no Art. $2^{\circ}$ da Constituição da República, o qual preleciona que:

A República Portuguesa e um Estado de direito democrático, baseado na soberania popular, no pluralismo de expressão e organização política democráticas, no respeito e na garantia de efectivacão dos direitos e liberdades fundamentais e na separação e interdependência de poderes, visando a 
realização da democracia económica, social e cultural e o aprofundamento da democracia participativa.

O Estado é de direito, pois tudo que envolve a sua organização político-estatal, bem como a sua composição, os ideais, fundamentos e outros não são escolhidos aleatoriamente, uma vez que seguem os parâmetros pelas disposições jurídicas constantes na legislação vigente. De outro bordo, a caracterização do Estado como democrático advém da ideia do poder tão somente pelo povo, longe de qualquer absolutismo ou totalitarismo.

Por último, vale ressaltar que um dos principais marcos do princípio do Estado Democrático de Direito é o grande peso conferido aos direitos fundamentais, que se sobressaem nos diversos ordenamentos jurídicos dos Estados sendo a razão da democracia.

Jurgen Habermas aponta que o Princípio Democrático e Princípio do Estado de Direito são interligados, ou seja, um não se realiza sem o outro. Todavia, isso não quer dizer que haja imposição de um ao outro. Explicando melhor, a autonomia privada solicita a autonomia pública e vice e versa, apesar de serem conceitos independentes e garantidos pelo direito político, é necessário que haja um entendimento, independência e consciência entre os cidadãos acerca das regras previstas no ordenamento. Para o citado autor por meio da teoria do discurso deve ser traduzido o modelo da auto legislação, sendo certo de que os participantes não são penas destinatários, mas criadores de seus direitos (JOSENDE, 2015).

\subsubsection{Direito ao voto e soberania popular}

Como bem preceitua Gomes Canotilho (2003) o poder do povo necessita para a sua efectivação uma legitimação democrática, tendo como alicerce principal a satisfação das necessidades do povo por meio da vontade política do mesmo.

No âmbito constitucional tal princípio é vinculante e é reforçado por direitos fundamentais, como por exemplo o direito a igualdade, o direito à liberdade política que se materializam como instrumentos de garantia do funcionalismo prático do citado princípio, conforme Art. $2^{\circ}$ e $10^{\circ}$ da CRP.

Não obstante, a terminologia "soberania" se perfaz como a característica do poder que controla os demais poderes e na teoria não é controlado. Nada mais é do que um adjetivo desta capacidade de deliberação, conferindo-lhe um papel de destaque. Em que pese o poder seja soberano, surge a segunda característica deste poder, a qual seja o aspecto democrático, inexistindo legitimação ao exercício arbitrário. É por esta razão que o poder soberano popular é essencial a instrumentalização dos deveres e garantias fundamentais como prevê a Constituição da República Portuguesa, a exemplo o Art. $3^{\circ}$. 
A partir disto é possível aferir que o princípio da soberania popular é multiforme, posto que a sua instrumentalização no ordenamento jurídico ocorre por meio de diversos institutos consagrados. Por consequência, entende-se como infundada a concepção de soberania popular dissociado do direito ao voto, até mesmo como forma de obediência ao princípio da igualdade.

Quanto a sua relação com os direitos fundamentais, Miranda (2018) frisa que existe uma interligação entre dois princípios classificados como substantivos, o quais são o princípio da soberania popular o princípio dos direitos fundamentais e a mediação de princípios tido com adjetivos do constitucionalismo e da legalidade. Nas palavras do referido autor:

Numa postura extrema de irrestrito domínio da maioria, o princípio democrático poderia acarretar a violação do conteúdo essencial dos direitos fundamentais; assim como, levado aos últimos corolários, o princípio da liberdade poderia recusar qualquer decisão jurídica sobre a sua modelação. $\mathrm{O}$ equilíbrio ou se preferir, a síntese, obtém-se através de uma complexa articulação de órgãos políticos e jurisdicionais com graduações conhecidas (Miranda, 2018, p. 255).

Habermas entende que os direitos à liberdade e a igualdades recebem, primeiramente, uma justificativa com fulcro na autonomia moral das indivíduas, para que, posteriormente sejam reencontrados e assegurados pela autonomia de cada um no exercício da cidadania, por consequência, pela autonomia pública (DUTRA, 2012).

\subsubsection{Sufrágio universal e o pleno direito ao voto}

O termo sufrágio deve ser interpretado como uma manifestação direta ou indireta de assentimento de certa proposição, ou seja, no ordenamento jurídico é a livre manifestação do anseio do povo na escolha de seus governantes, por meio do apoio aos ideais propagados.

Nesse sentido, está a jurisprudência do Tribunal Constitucional de Lisboa, no Acórdão 602/89² que expõe que o princípio democrático é universal, bem como o sufrágio, que está histórica e essencialmente ligado ao direito da participação na formação da vontade geral, como exposto no Art. $6^{\circ}$ da Declaração dos Direitos do Homem e do Cidadão de 1791 e o artigo 21. ${ }^{\circ}$ da Declaração Universal dos Direitos do Homem.

Segundo o jurista José Jairo Gomes (2016), o sufrágio está ligado diretamente ao exercício do princípio da soberania popular, posto que se revela como a capacidade ativa por

\footnotetext{
2 ACÓRDÃo No 602/89. Processo: n. ${ }^{\text {o } 323 / 89 . ~ P l e n a ́ r i o ~ R e l a t o r: ~ C o n s e l h e i r o ~ S o u s a ~ e ~ B r i t o . ~ L i s b o a, ~} 7$ de dezembro de 1989. José de Sousa e Brito. António Vitorino, Messias Bento, Vitor Nunes de Almeida, Fernando Alves Correia, Maria da Assunção Esteves, Bravo Serra, Antero Alves Monteiro Diniz, Alberto Tavares da Costa, Armindo Ribeiro Mendes, José Manuel Cardoso da Costa (tem voto de conformidade do Sr. Conselheiro Luís Nunes de Almeida, que não assina por não estar presente), José de Sousa e Brito". Disponível em: http://www.tribunalconstitucional.pt/tc /acórdãos/19890602.html. Acesso em 18 de julho de 2020
} 
meio do direito ao voto e capacidade passiva caracterizada pela possibilidade do cidadão de ser um representante popular, ou seja, ser votado. Desse modo, o sufrágio universal poder ser entendido como a raiz dos direitos políticos, posto que possibilita a atuação do povo na condução estatal.

Vale esclarecer que apesar da universalidade do sufrágio, o exercício dos direitos eleitorais de votar e ser votado não engloba indiscriminadamente todo e qualquer indivíduo. Isso porque é necessário preencher os requisitos estabelecidos em lei para tanto. Na hipótese do Direito português, por exemplo, esses parâmetros estão consolidados no Art. 10. ${ }^{\circ}$ da Constituição da República de Portugal, mais especificamente no Art. 10.

No que cerne a relação do sufrágio universal com os direitos fundamentais, entende-se que o mesmo é oriundo do princípio da isonomia. Uma vez que os cidadãos são postos no mesmo nível, de modo que o voto individual tem o mesmo valor e o mesmo peso na contagem de votos, ainda que haja diferenças econômicas, de gênero, naturalidade e outros entre os eleitores.

Outro ponto que merece destaque, é a diferenciação entre voto e sufrágio. Para melhor esclarecimento, é válido dizer que o sufrágio é o direito ao voto, enquanto que o voto é a própria operacionalização do sufrágio, assumindo natureza, não apenas de direito, mas de dever cívico. Ressalta-se, ainda, que é um dever também do Estado proporcionar ao cidadão todos os meios que possibilitem a o exercício do seu direito.

Vale ressaltar que em Portugal, diferentemente de como corre no Brasil, o voto não é obrigatório, mas facultativo, podendo ser exercido por qualquer cidadão português após os 18 anos, sendo assim pode ser considerado apenas como um direito que vai ao encontro da liberdade do indivíduo.

Para aqueles que decidem exercer tal direito, este deve fazer de maneira presencial, não sendo permitida qualquer outra maneira de representação para seu exercício, conforme o Art. 12 da Lei n. ${ }^{\circ}$ 29/2015, exceto para os eleitores que moram fora do país, podendos estes enviar seus votos por correios, dentro do prazo estipulado de cordo com as normas estabelecidas.

De acordo com a mesma lei, em seu Art. 13, pessoas com deficiência que possuem qualquer dificuldade para exercer o direito de votar, podem ser acompanhados por outro eleitor, garantindo assim a fidelidade de expressão de sua escolha.

O voto em Portugal é realizado por meio da marcação no local indicado, nos boletins de voto, que possuem forma retangular, de cor definida pela CNE, onde estão as listas de candidatos, na ordem disposta por sorteio efetuado nos termos do Art. 5..$^{\circ}$ sendo automaticamente anulados em caso de rasuras (CNE, 2021, n.p.). 
A Constituição Portuguesa não adentrar na seara de estruturação do boletim de voto, apenas em estruturar as garantias conducentes a um sufrágio universal, ao voto secreto, e também direto (art. $10^{\circ} \mathrm{CRP}$ ), que garanta com que o eleitor se conduza de forma segura, até a cabine eleitoral.

A estruturação do boletim consta do artigo $14^{\circ}$ e $15^{\circ}$ da LEAR: onde determina que a apresentação da candidatura é por lista; o voto é, portanto, de lista (em lista partidária); sendo este voto único (singular).

De acordo com o $15^{\circ}$ da LEAR, a lista é ordenada pelo partido, sem que haja possibilidade de o eleitor produzir-lhe qualquer modificação e na tentativa, o voto fica nulo. A doutrina chama este tipo de boletim de lista fechada, sendo que a mesma não pode ser inferior ao número de cargos em disputa, compondo-se, ainda, com, no mínimo, mais dois suplentes ( $\operatorname{Art} .15^{\circ}$ ).

\subsubsection{Princípio Republicano}

É possível afirmar que nos dias atuais há duas formas de governos mais comuns entre os Estados, as quais são a república e a monarquia. A monarquia tem como traços principais a hereditariedade e a vitaliciedade, enquanto que a república tem como característica a eletividade, a rotatividade e a temporalidade, que fazem com que haja uma alternância nos representantes do povo no poder, sendo essa segunda forma a exercida em Portugal.

Logo, os poderes dos chefes do Executivo e do Legislativo estão intimamente ligados aos seus respectivos mandatos e que se enquadra à perspectiva de representatividade abordada anteriormente, por meio de eleições periódica, gerais e diretas com fulcro no direito fundamental da liberdade de escolho conferido aos cidadãos.

A título de exemplo, cita-se a previsão legal do referido princípio, conforme Arts. $128 .^{\circ}$ e 123. ${ }^{\circ}$ da CRP, o mandato do Presidente da República dura no máximo cinco anos sendo que pode ser reeleito para um segundo mandato em seguida, mas não para um terceiro, devendo esperar dez anos, para uma nova eleição, caso tenha sido eleito por duas vezes consecutivas.

É importante pontuar que o princípio em comento se revela como uma forma de proteção da democracia, uma vez que impede a perpetuação do poderio nas mãos dos representantes eleitos. Desse modo, o Estado é oxigenado pela rotatividade dos eleitos, refletindo diretamente os anseios populares e as mutações naturais da sociedade.

Ainda, ressalta-se, que o princípio republicano promove a soberania popular, pois possibilita que o povo manifeste sua vontade, por meio do voto, podendo reeleger o mesmo candidato ou outro, dando equilíbrio, quando não permite um terceiro mandato consecutivo, 
como já exposto anteriormente. Ainda, para que haja equidade plena, nas eleições, existe a adoção do princípio da igualdade dos votos, em que cada distrito deve ser proporcional ao número de eleitores (Art. 13º , n. 2 da Lei Eleitoral para Assembleia da República -LEAR).

\subsubsection{Princípio da legitimidade}

A concepção do termo legítimo está entrelaçada com os valores inerentes à justiça, presumindo a observância do devido processo legal. Logo, é dito legítimo, algo reputado por correto, justo e adequado. No cenário atual, a noção de legitimidade do poder conferido aos governantes tem origem no processo eleitoral limpo e justo que resultou na sua eleição.

Neste vértice, corrobora-se a importância de um processo de eleição transparente e honesto, com o cumprimento estrito dos ditames legais previstos no ordenamento jurídico, pois é a obediência a tais procedimentos que garantem a legitimidade.

Apesar da semelhança, não deve se confundir legalidade com legitimidade, uma vez que o segundo não se limita ao direito positivo, atua no plano subjetivo, ou seja, é a sensação por parte do povo de que os representantes eleitos é expressão da sua vontade na qualidade de cidadão.

\subsubsection{Princípio da Moralidade Eleitoral}

O representante eleito no curso do seu mandato deve ser vigilante aos ideais éticos, não se limitando a obediência apenas das imposições legais, tendo discernimento do que é honesto ou não. Tal princípio objetiva refletir o sentimento por parte da população de um governo justo, uma que cansada de sofrer abusos por parte das autoridades, que na maior parte das vezes busca a satisfação unicamente dos seus próprios interesses, ignorando tudo aquilo que é moral.

Sobre o tema, convém citar a palavras do jurista brasileiro, ainda dentro dessa temática, são precisas as palavras de Celso Antônio Bandeira de Mello:

Compreendem-se em seu âmbito, como é evidente, os chamados princípios da lealdade e boa-fé, tão oportunamente encarecidos pelo mestre espanhol Jesús Gonzáles Peres em monografia preciosa. Segundo os cânones da lealdade e da boa-fé, a Administração haverá de proceder em relação aos administrados com sinceridade e lhaneza, sendo-lhe interdito qualquer comportamento astucioso, eivado de malícia, produzindo de maneira confundir, dificultar ou minimizar o exercício de direitos por parte dos cidadãos (MELLO apud TAVARES, 2008 , n. p.).

Outro ponto que merece destaque é que conquanto haja similitudes entre o princípio da legalidade e o da moralidade, estes não devem ser confundidos entre si, uma vez que há situações que são ditas como imorais apesar de não haver expressa vedação legal. 
Segundo Souza (2009), tais violações ao princípio da moralidade revelam-se de forma camuflada, como, por exemplo, os tratamentos discriminatórios por parte dos administradores. Logo, embora não haja violação ao princípio da legalidade, há afronta direta aos princípios da moralidade e impessoalidade.

\subsubsection{Princípio da representatividade}

Conforme exposto anteriormente, o princípio democrático indica a participação direta ou indireta da população, respectivamente por meio de plebiscitos e referendo ou por meio de seus representantes legais. Portanto, pacifica-se o entendimento de que a efetivação de tal regime não poderia ser de outra forma, tendo em vista que o Estado cujo fim precípuo o bem comum do seu povo e é originado pelo poder conferido aos cidadãos.

De outra vértice, o princípio da representatividade é o instrumento legal de realização da a democracia indireta. Uma vez que o povo elege representantes para a ocupação de cargos políticos e estes ao serem revestidos do poder se incubem da defesa dos interesses da população, legislando, fiscalizando ou executando ações estatais.

O Direito português fixa os ideais do referido princípio por meio do texto legal do Art. 147. da Constituição Portuguesa, que prevê que a Assembleia da República é representativa de todos os cidadãos, sendo que pelo seu Art. $121^{\circ}$, expõe que os cidadãos portugueses elegem por sufrágio universal, o Presidente da República pelo o voto secreto. Nesse ponto ainda explica que têm direito ao voto, cidadão portugueses residentes no país e também os residentes no estrangeiro.

Acerca do assunto, assevera Jorge Morais (2005, p. 32):

Governo representativo significa a forma de governo em que se opera uma dissociação entre a titularidade e o exercício do poder - aquela radicada no povo, na nação (no sentido revolucionário) ou na colectividade, e este conferido a governantes eleitos ou considerados representativos da colectividade (de toda a colectividade, e não de estratos ou grupos como no Estado estamental). E é uma forma de governo nova em confronto com a monarquia, com a república aristocrática e com a democracia directa, em que inexiste tal dissociação.

É possível extrair dos ensinamentos de Gomes Canotilho (2003) que os alicerces do princípio da representatividade pautam-se na autorização constitucional do exercício jurídico de órgão da soberania do Estado feitos em nome do povo, por meio da legitimação de domínio derivada do princípio da soberania do Estado com o objetivo de satisfação do interesse comum. Ou seja, na visão do jurista português, a noção de representatividade está intrinsicamente ligada 
a outorga de poder dada pelo povo a um ente soberano que apesar da autonomia na tutela do direito do povo.

Neste caso, aponta-se os partidos políticos como como os responsáveis pela representatividade da opinião pública de diferentes grupos sociais que se identificam com a bandeira e os interesses do partido nas lutas políticas.

\subsection{Princípios da propaganda eleitoral}

Já tendo sido elucidado os aspectos referentes aos princípios eleitorais constitucionais e sua relação intrínseca aos direitos fundamentais, outro ponto merece ser abordado, o qual seja a propaganda eleitoral e seus princípios. Isso porque como abordado é necessário que o indivíduo possua autonomia para poder exercer sua cidadania e o principal meio de influência na livre convicção dos cidadãos é a propaganda utilizada nas campanhas eleitorais.

Em enfoque ao primeiro princípio que é a liberdade de propaganda, observa-se que há uma relação direta e intrínseca com o direito fundamental a liberdade de expressão. Conforme preleciona o Art.19 da Declaração Universal de Direitos Humanos.

Inicialmente é importante trazer o conceito de propaganda, segundo Pimentel (2019) consiste na difusão intencional de uma ideia, de uma ideologia, de um produto ou crença

religiosa. É por meio dela que o candidato tenta criar uma opinião favorável à sua candidatura ou ao seu mandato, ou seja, é o meio pelo qual se passa a mensagem ao receptor.

Desta feita, pontua-se que a propaganda política é gênero, tendo como espécies a propaganda eleitoral, a institucional, a intrapartidária e a partidária, sendo lícito a arrecadação de votos para o partido e o candidato por meio do pedido direto apenas na propaganda eleitoral.

Em face da importância e do peso que possui na influência ao voto, pode se extrair dos estudos doutrinários e da jurisprudência alguns princípios que regem especificamente a propaganda eleitoral, os quais merecem espaço no presente trabalho.

Primeiramente, temos o princípio da atuação ex officio ou princípio do controle judicial da propaganda, por este axioma temos a fiscalização, bem como a repressão da propaganda eleitoral por meio do poder de polícia que o juiz possui. Com efeito, o magistrado eleitoral tem suas atividades adstritas da fiscalização, independentemente de provocação por interessados.

Em segundo, registra-se o princípio da legalidade, o direito ao exercício da propagando deve obedecer às disciplinas estabelecidas pela Lei n. ${ }^{\text {o } 72-A / 2015}$, de 23 de julho, a qual regulamenta o regime jurídico da cobertura jornalística em período eleitoral e normatiza a propaganda eleitoral através de meios de publicidade comercial, tendo aplicabilidade lato sensu 
a todos os atos eleitorais e referendários. Ademais, há a Lei Eleitoral da Assembleia da República n. ${ }^{\circ}$ 14/79, de 16 de maio que é responsável por disciplinar as matérias atinentes ao Direito Eleitoral. Nesse ponto, vale frisar que o direito fundamental à liberdade de expressão não é absoluto, razão pela qual é disciplinado para se sujeitar a algumas restrições.

Outro princípio que merece destaque é da liberdade, o qual estabelece que dentro dos limites legais, é livre o exercício da propaganda. É necessário tecer comentários acerca do caráter não restritivo das normas que estabelecem os tipos de propaganda, pois não se tratam de um rol taxativo que se esgota nas hipóteses descritas.

O referido princípio é encontrado na fundamentação de diversos julgados do Tribunal Constitucional de Lisboa, conforme trecho colacionado a seguir:

Tudo visto, é doutrina consolidada desta Comissão e jurisprudência assente do Tribunal Constitucional (cf. 266/2011) que a cedência de espaços públicos de acesso reservado, prevista no artigo $63 .^{\circ}$ da Lei Eleitoral dos Órgãos das Autarquias Locais, concretiza o dever que a Constituição da República Portuguesa impõe ao Estado de garantir condições para uma efetiva liberdade de propaganda e de igualdade de oportunidades, sendo indiferente que tais espaços sejam do domínio público ou privado do Estado em sentido lato ou, ainda, que sejam geridos segundo as regras da administração pública ou dos negócios privados, bem assim, a natureza dos entes que concretizam essa gestão, desde que sejam pelo menos de capitais maioritariamente públicos. (grifos meu) ${ }^{3}$.

Assim, como em Portugal, também no Brasil, tal entendimento foi consolidado no RESP $\mathrm{n}^{\circ} 15065$, o qual cita-se a seguir:

A propaganda eleitoral que não possui regulamentação trata-se de propaganda ilícita, pois qualquer vedação a determinado tipo ou a determinada forma de propaganda deve ser expressa, sob pena de violação ao princípio da liberdade e da disponibilidade da propaganda política.

Por outro lado, pelo princípio da isonomia entre candidatos e partidos de modo a assegurar que todos terão o direito de acesso à propaganda política. Segundo Pimentel (2019) ao interpretar o citado princípio deve haver uma ressalva de que devem ser tratados de maneira igual os candidatos que estão em condição de igualdade e desigual os que encontrarem em patamar de desigualdade.

Nesse sentido, é interessante colacionar trecho do Acórdão n. ${ }^{\circ}$ 461/2017 do Tribunal Constitucional, o qual assegura o cumprimento fático do citado princípio:

3 Lisboa, 27 de setembro de 2017. Catarina Sarmento e Castro - João Pedro Caupers - Pedro Machete - Lino Rodrigues Ribeiro - Fernando Vaz Ventura - Maria Clara Sottomayor - Gonçalo Almeida Ribeiro - Maria José Rangel de Mesquita - Claudio Monteiro - José Teles Pereira - Maria de Fátima Mata-Mouros - Joana Fernandes Costa - Manuel da Costa Andrade. Disponível em: http://www.tribunalconstitucional.pt/tc/acordaos/20170584.ht ml. Acesso em: 19 de agosto de 2020. 
[...], o Tribunal Constitucional tem reconhecido, por referência à alínea d) do n. ${ }^{\circ} 1$ do artigo $5 .^{\circ}$ da Lei n. $^{\circ} 71 / 78$, de 27 de dezembro - "[a]ssegurar a igualdade de oportunidades de ação e propaganda das candidaturas durante as campanhas eleitorais" - que a CNE é competente para a apreciação da legalidade de atos de publicidade institucional, com o intuito de impedir a prática de atos por entidades públicas que favoreçam ou prejudiquem uma candidatura em detrimento ou vantagem de outra (ACÓRD ̃̃O n. ${ }^{\circ}$ 461/2017). (grifos meu)

Como se vê, todos esses princípios são formas de regulamentar o direito à propaganda, pois muito embora a liberdade de expressão seja um direito fundamental, na seara eleitoral deverá ser submetido ao interesse da coletividade. Posto que todas as ações e omissões relacionadas a ambição pelos cargos públicos e todas as são de interesse geral e sua livre publicação é uma forma de proteção à autonomia dos cidadãos.

Desse modo, os casos que violem os ditames legais por meio de abusos, difamações, declarações inverídicas e outros deverão ser fiscalizados e julgados pelos órgãos competentes para receber as reprimendas necessárias. De sorte que é mais importante para a população viver realmente um Estado de Direito e ter o direito de se expressar, bem como de ouvir as ideias políticas, pois conforme Habermas, não há autonomia pública se não houver autonomia privada (DIAS, 2014).

\subsubsection{A tutela na propaganda eleitoral em Portugal}

Como já foi especificado, a propaganda eleitoral é direito do candidato, no que concerne à liberdade de expressão, no entanto, o candidato deve respeitar os princípios da legalidade, do poder de polícia ex officio, bem como outros princípios eleitorais que regem a propaganda.

A campanha eleitoral, no sentindo amplo, possui os princípios regentes consagrados constitucionalmente no Art. 113, no 3 da CRP. Segundo o CNE classificam-se em: a) o Princípio da liberdade de propaganda; b) Princípio da igualdade de oportunidades e tratamento das diversas candidaturas; c) Princípio da imparcialidade das entidades públicas perante as candidaturas; d) Princípio da transparência e fiscalização das contas eleitorais.

A CNE - Comissão Nacional de Eleições 2021 expõe que a campanha eleitoral é possível a todo o tempo, pois o apelo é livre, no entanto existem algumas ressalvas previstas, que serão fiscalizadas e julgadas pelos órgãos competentes para receber as reprimendas necessárias em caso de violação das regras, como se vê a seguir:

Fica proibido afixar propaganda em centros históricos, como monumentos nacionais, templos, edifícios oficiais do Estado, locais públicos onde as assembleias ocorrerão, nos sinais de trânsito e placas de sinalização rodovias e ferrovias, Regiões Autónomas e das autarquias 
locais e toda e qualquer repartições públicas, exceto, quanto se destinam à convivência de funcionários e agentes de campanha. Também fica proibido escrever ou fazer pinturas em muros destes locais citados (CNE, 2021, n.p.).

Em Portugal há espaços se que destinam à afixação de propagandas eleitoras, como nas câmaras municipais. As juntas de freguesia são responsáveis por disponibilizar espaços adicionais que serão usados para esse fim e estes espaços devem ser distribuídos de forma equitativa, durante o período legal de campanha. As propagandas ainda podem ser afixadas em espaços privados, desde que autorizado pelo proprietário (CNE, 2021, n.p.).

Além disso os candidatos que estiverem concorrendo aos órgãos municipais, câmara e assembleia municipal, têm direito à emissão de antena, que são transmitidos nas rádios locais, e também deve ser realizado de forma igual entre os concorrentes. Ohman (2015) assegura que o financiamento público permite que todas as forças políticas importantes acessem os recursos hábeis a fim de atingir o eleitorado, incentivando o pluralismo político e fornecendo ao eleitor possibilidades de escolha das políticas sociais em discussão.

Ainda, em Portugal, todos os candidatos têm direito ao espaço televisionado, pago pelo Estado, equitativamente, não podendo o candidato comprar por espaço extra, sem que o conteúdo seja editado, essa decisão objetiva garantir que todos têm as mesmas condições e que não são condicionados por decisões ou critérios editoriais.

Fica proibido também a propaganda, de qualquer espécie, na véspera e no dia das eleições e caso isso ocorra o candidato pode ser punido com pena de multa de no mínimo 100 dias ou pena de prisão de até seis meses. Inclusive não pode haver propaganda nas imediações das assembleias de voto na data das eleições, respeitando uma distância de 50 metros destes locais, bem como toda e qualquer propaganda que fica visível da assembleia (CNE, 2021, n.p.).

Nas sedes partidárias podem haver propagandas no dia das eleições desde que atendam aos requisitos impostos pela Comissão Nacional de Eleições (CNE, 2021, n.p.).

Inclusive, o cidadão pode prestar queixa por propaganda que estejam sendo afixadas de forma irregular junto à Câmara Municipal, à Junta de Freguesia, à Comissão Nacional de Eleições, bem como em outras entidades públicas, como, por exemplo, aos bombeiros.

Após as eleições as propagandas podem ser retiradas, pelo próprio proprietário do local de afixação e não existe um prazo legal para essa remoção. A Câmara municipal, a pedido, também faz remoção e, no caso de o espaço ser privado, e as custas cabem às entidades responsáveis pela afixação (CNE, 2021, n.p.).

É importante destacar que hoje, com o advento das novas tecnologias, existem várias maneiras de se fazer propaganda eleitoral, como por meio de e-mails, podcasts, aplicativos de 
mensagens, sites, redes sociais, entre outros. Essas campanhas podem ser realizadas em Portugal, pois compactua com os princípios da liberdade de expressão. No entanto existe por parte dos órgãos competentes, uma recorrente preocupação com a circulação de fake News, por isso o país se juntou à União Europeia no combate às desinformações: "Combater as Fake News - Uma Questão Democrática (COMISSÃO EUROPEIA, 2021, n. p.)

\section{Conclusão}

No que cerne ao primeiro capítulo foi possível aferir que a norma jurídica é composta por regras e princípios. Enquanto que o conflito de regras é solucionado a luz do plano da validade, a antinomia principiológica é resolvida na dimensão de peso. No que cerne à relação entre os princípios e os direitos fundamentais, observa-se a importância da dignidade da pessoa humana, uma vez que é a razão do surgimento do Estado Democrático de Direito.

Concernente ao direito eleitoral, verifica-se que há princípios classificados como políticos constitucionais estruturantes. Isso porque são responsáveis por organizar o regime político, a estrutura do Estado e outros. Tais princípios foram abordados no quarto tópico do presente trabalho. Inicialmente temos o princípio democrático que reproduz as vertentes da teoria democrática representativa, os quais sejam a separação de poderes, o pluripartidarismo, eleições e representatividade por órgãos. Em complementariedade temos o princípio do Estado Democrático de Direito que assegura os direitos fundamentais de associação, de liberdade de expressão e de formação de partido político.

No que diz respeito ao princípio da soberania popular, no âmbito constitucional tal princípio é vinculante e é reforçado por direitos fundamentais, como por exemplo o direito a igualdade, o direito à liberdade política. Exsurge, ainda, o princípio republicano como forma de oxigenação da democracia, por meio da rotatividade dos eleitos. Nessa esfera temos o princípio da representatividade, o qual garante à população ser representada junto ao Poder Público por um partido com ideais e propostas que lhe interessam. Todavia, a instrumentalização de todos esses pontos abordados se dá por meio do sufrágio universal, expressado pelo direito fundamental ao voto. Pois, segundo Habermas, para que o Estado de Direito seja legitimamente democrático é necessário consciência por parte dos cidadãos por meio do exercício da autonomia privada.

É partindo dessa assertiva que surge os princípios inerentes ao direito à propaganda, tendo vista que é por meio dela que é formada a convicção do eleitor acerca do panorama política. De um lado temos o direito constitucional à liberdade de expressão, de outro temos os princípios 
do poder de polícia ex officio, o princípio da legalidade, da igualdade entre candidatos e outros que normatizam o exercício do citado direito, uma vez que não se trata de um direito absoluto, não podendo o eleitor ser induzido a erro.

\section{REFERÊNCIAS}

ACÓRDÃO $\mathrm{n}^{\text {o }}$ 602/89. Lisboa, 7 de dezembro de 1989. Disponível em: http://www.tribunalconstitucional.pt/tc/acorda os/198 90602.html. Acesso em: 18.07.2020

ACÓRDÃO $\mathrm{n}^{\text {o }}$ 461/2017. Lisboa, 24 de agosto de 2017 - Disponível em: http://www.tribunalconstitucional.pt/tc/acordaos/20170460.html. Acesso em: 22.08.2020

ACÓRDÃO $\mathrm{n}^{\mathrm{o}}$ 254/2019. Lisboa, 27 de setembro de 2017. Disponível em: http://www.tribunal constitucional.pt/tc/acordaos/20170584.html. Acesso em: 19.08.2020.

ARAGÃO, Gerson. Qual a diferença entre regras e princípios? (segundo Robert Alexy). Revista de informação legislativa, v. 42, n. 165, p. 123-134, jan./mar. 2005. Disponível em: https://gersonaragao.jusbrasil.com.br/artigos/215342544/qual-a-diferenca-entre-regras-eprincipios-segundo-robert-alexy. Acesso em: 22.08.2020.

ÁVILA, Humberto. Teoria dos Princípios: da definição à aplicação dos princípios jurídicos. $15^{\text {a }}$ ed. São Paulo: Malheiros, 2014.

CANOTILHO, José Joaquim Gomes. Direito Constitucional e teoria da Constituição. 7. ed. Coimbra: Almedina, 2003.

COMISSÃO EUROPEIA. Moldar o futuro digital da Europa - Combatendo a desinformação online. 2021. Disponível em: https://digital-strategy.ec.europa.eu/en/policies/onlinedisinformation. Acesso em: 19.08.2020

COSTA, Daniel Castro Gomes da. Curso de Direito Processual Eleitoral. Belo Horizonte: Fórum, 2018.

CONSTITUIÇÃO DA REPUBLICA PORTUGUESA DE 1976. Disponível em: https://www.parlamento .pt/Legislacao/ Paginas/ConstituicaoRepublicaPortuguesa.aspx.

Acesso em: 20.08.2020

CUNHA JUNIOR, Dirley da. Curso de direito constitucional. Salvador, Imprenta: Salvador, 2012. ISBN: 9788544219263.

DECLARAÇÃO UNIVERSAL DOS DIREITOS HUMANOS. Disponível em: https://nacoesunidas.org/wp-content/uploads/2018/10/DUDH.pdf. Acesso em: 23.08.2020

DECLARAÇÃO DOS DIREITOS DO HOMEM E DO CIDADÃO 1789. Disponível em: http://www.direitoshumanos.usp.br/index.php/Documentos-anteriores-\%C3\%A0cria\%C3\%A7\%C3\%A3o-da-Sociedade-das-Na\%C3\%A7\%C3\%B5es-at\%C3\%A9-19 19/declaracao-de-direitos-do-homem-e-do-cidadao-1789.html. 2020. Acesso em: 24.08.2020

DIAS, Jorge Andersson Vasconcelos. Apontamentos sobre as noções de autonomia pública e privada em Jürgen Habermas. 2014. Disponível em: http://conteudojuridico.com.br/consulta/Artigos/41980/apontamentos-sobre-as-nocoes-deautonomia-publica-e-privada-em-jurgen-habermas. Acesso em: 27.08.2020

DUTRA, D. J. V. Rousseau e Habermas. Argumentos, ano 4, n. 18, 2012. 
DWORKIN, Ronald. Levando os direitos a sério. 3. ed. São Paulo: WMF Martins Fontes, 2013.

FERREIRA, Pinto. Código Eleitoral Comentado. 3 ed. Coimbra: Almedina, 2003.

GOMES, José Jairo. Direito Eleitoral, 12ª ed., São Paulo: Atlas, 2016. ISBN: 978-85-9700384-0.

JOSENDE, Lauriane. Le paradoxe de létat de droit démocratique, trad. In Les temps Modernes. Teoria Política, trad. Lisboa, 2015.

LEI N. ${ }^{\circ}$ 29/2015. Primeira alteração à Lei n. ${ }^{\circ}$ 66-A/2007, de 11 de dezembro, que define as competências, modo de organização e funcionamento do Conselho das Comunidades Portuguesas. Assembleia da República. Disponível em: http://www.cne.pt/sites/default/files/dl/ccp_2015_portaria_197_2015-

regulamenta_o_processo_eleitoral.pdf. Acesso em: 10 Mar. 2021

LEI 13.165- 2015. Altera as Leis $n^{\circ}$ 9.504, de 30 de setembro de 1997, 9.096, de 19 de setembro de 1995, e 4.737, de 15 de julho de 1965 [...]. Disponível em: http://www.planalto.gov.br/ccivil_03/_ato2015-2018/2015/lei/113165.htm. Acesso em: 10 Mar. 2021

LEI ELEITORAL DA ASSEMBLEIA DA REPÚBLICA N. ${ }^{\circ}$ 14/79. Disponível em: http://www.cne.pt/sites/ default/files/ dl/legis_lear_2012_0.pdf. Acesso em: 21.08.2020

LEI N. ${ }^{\circ}$ 72-A/2015. Disponível em: https://dre.pt/pesquisa/-/search/69866640/details/ maximized. Acesso em: 22.08.2020

LEI ORGÂNICA n. ${ }^{\circ} 3 / 2020$, de 11 de novembro. Disponível em: http://www.cne.pt/sites/default/files/dl/legis_lo-3-2020_regime_excecional_e_temporariovoto_antecipado-eleitores_em_confinamento_obrigatorio.pdf. Acesso em: 08.04.2021

MAZZUOLI, Valério de Oliveira. Curso de direitos humanos - 5. ed., rev. atual. ampl. São Paulo: Método, 2018.

MIRANDA, Jorge. Direitos Fundamentais: Introdução Geral, Lisboa, 2018.

MIRANDA, Jorge. Teoria Do Estado e da Constituição, 2005.

NOVAIS, Jorge Reis. A dignidade da pessoa humana. $2^{\text {a }}$ ed. (Manuais universitários) V.I: Dignidade e direitos fundamentais. Coimbra: Almedina, 2018. ISNN 978-972-40-7591-4.

OHMAN, Magnus. Entendimento do Sistema de Financiamento Político. Financiamento de partidos políticos e campanhas eleitorais: um manual sofre financiamento político. 1.ed. Rio de Janeiro: FGV Editora, 2015.

PIMENTEL, Alexandre Freire. Propaganda eleitoral: poder de polícia e tutela provisória nas eleições/Alexandre Freire Pimentel. Belo Horizonte: Fórum, 2019.

RESP. no 15065/BA. Relator Mauricio Jose Correa. Acórdão de 21/10/2015. Disponível em: https://stj.jusbrasil.com.br/jurisprudencia/586255/recurso-especial-resp-15065. Acesso em: 19.08.2020.

SOUZA, Rubin Assis da Silveira. Distinção entre moralidade e legalidade no pensamento de Kant segundo Bobbio. Revista Jus Navigandi, Teresina, ano 14, n. 2320, 7 nov. 2009. Disponível em: https://jus.com.br/artigos/13817. Acesso em: 26.08.2020

TAVARES, Gustavo Machado. O princípio da moralidade como fundamento para o indeferimento de registro de candidatura. Revista Jus Navigandi, Teresina, ano 13, n. 1921, 4 out. 2008. Disponível em: https://jus.com.br/artigos/11805. Acesso em: 26.08.2020 